\title{
AVALIAÇÃO DE SISTEMA DE COLUNAS PARA REMEDIAÇÃO DE BIOGÁS A PARTIR DE BIOMASSA NÃO DIGERIDA
}

\author{
V. PEREIRA, J. M. FERREIRA-JR, G. A. S. MARTINEZ* e C. R. TOMACHUK \\ Escola de Engenharia de Lorena da Universidade de São Paulo (EEL-USP) \\ gustavo.martinez@usp.br*
}

Artigo submetido em janeiro/2015 e aceito em dezembro/2015

DOI: $10.15628 /$ holos.2015.2688

\section{RESUMO}

O biogás é produto de reações de biomassa e constitui um combustível gasoso em temperatura ambiente, com conteúdo energético elevado que pode ser comparado aos combustíveis de origem fósseis pois é semelhante ao gás natural. Devido ao seu alto poder energético pode ser utilizado para geração de energia elétrica, térmica ou mecânica, reduzindo os custos de produção. O processo de biodigestão anaeróbia consiste em metabolizar substâncias orgânicas complexas produzindo metano, dióxido de carbono, gases em menor quantidade (sulfídrico e hidrogênio) e material celular. Como subproduto da produção de metano, o dióxido de carbono é o que apresenta maior quantidade, e por ser um gás não-inflamável, pode ser definido como um subproduto indesejável da produção de biogás. Este trabalho teve como objetivo separar o dióxido de carbono, produzido na fermentação anaeróbica, por precipitação em reação com hidróxido de bário; obtendo como produto gerado o carbonato de bário, que apesar de tóxico é utilizado por diferentes indústrias. O processo adotado objetiva encontrar uma metodologia e aproveitar economicamente o dióxido de carbono gerado em biodigestores diminuindo o efeito estufa provocado pela emissão do mesmo no meio ambiente.

PALAVRAS-CHAVE: dióxido de carbono, hidróxido de bário, biogás, biomassa

\section{COLUMN SYSTEM EVALUATION FOR BIOGAS REMEDIATION FROM BIOMASS NOT DIGESTED}

\section{ABSTRACT}

Biogas is a product of biomass reactions and it consists of a gaseous fuel at room temperature with high energetic content that can be compared to those from fossil fuels because it is similar to natural gas. It can be used to generate electrical, thermal or mechanic energy reducing the cost of production due to its high energetic power. The anaerobic biodigestion process consists in metabolizing complex organic substances producing methane, carbon dioxide, gases in lower quantity (sulfide and hydrogen) and cellular material. As a byproduct in methane production, carbon dioxide is what shows
\end{abstract}

higher quantity and for not being inflammable, it can be defined as an undesirable byproduct in biogas production. This work aims to separating carbon dioxide, produced in the anaerobic fermentation, due to the precipitation in reaction with barium hydroxide; producing barium carbonate; and in spite of being toxic, it can be used in different industries. The adopted process aims to finding a methodology and seize economically of the generated carbon dioxide in biodigestors reducing the greenhouse effect caused by its emissions to the environment.

KEYWORDS: carbon dioxide, barium hydroxide, biogas, biomass 


\section{INTRODUÇÃO}

A reciclagem de resíduos orgânicos para produção de energia é tema relevante no contexto atual do desenvolvimento humano. Os processos de biodegradação dos produtos naturais e sintéticos vêm sendo extensivamente estudados com o intuito de descobrir mecanismos capazes de amenizar os impactos causados pela produção e descarte de resíduos no meio ambiente. Uma das possibilidades de aproveitamento destes resíduos é a utilização de biodigestores que geram metano como fonte de energia.

Nesse contexto, esse trabalho tem como objetivo apresentar uma proposta para remover gases prejudiciais gerados em um biodigestor, com o propósito de obter gás metano praticamente puro.

\section{REFERENCIAL TEÓRICO}

O aquecimento global, poluição urbana, escassez de reservas de petróleo e combustíveis com alto custo têm sido os principais fatores no desenvolvimento de pesquisas sobre o uso de fontes alternativas de energia, particularmente aquelas provenientes de fontes de biomassa. Atualmente são investidos grandes quantidades de recursos na procura por tecnologias limpas, que são formas eficazes de minimizar os efeitos ao meio ambiente. As novas tecnologias denominadas limpas têm, a priori, que possibilitar a redução do uso dos recursos naturais esgotáveis (YADVIKA, 2004).

Segundo Ribeiro (2011) destacam-se como benefícios da utilização dos biodigestores: produção de biogás, descontaminação biológica e química dos dejetos animais e a geração de biofertilizante por meio de processo anaeróbico.

Em uma busca patentária com a palavra "biodigestor", na base de dados do site Aulive (2015), foram encontrados 131 patentes das quais 89 são brasileiras, entre elas destacam-se alguns biodigestores como o que possui um bolsão hermético resistente posto diretamente no solo, mostrando que tal processo se tornou muito eficiente (SAKA, 2013) e o biodigestor feito de mantas plásticas (HONDA, 2009).

Vale ressaltar que a transformação da matéria orgânica em diversas substâncias químicas, no curso da fermentação anaeróbica, processa-se por meio de degradações sucessivas devido a diferentes tipos de bactérias (MURTO, 2004).

Conforme Moraes (2014), as fases da digestão anaeróbica são cinco, a saber:

- hidrólise: que é realizada por enzimas exógenas convertendo particulados em dissolvidos.

$$
\mathrm{C}_{6} \mathrm{H}_{12} \mathrm{O}_{6} \rightarrow 2 \mathrm{CO}_{2}+2 \mathrm{C}_{2} \mathrm{H}_{5} \mathrm{OH}
$$

- acidogênese: é a metabolização e conversão em compostos mais simples tendo como principal produto ácidos graxos.

$$
2 \mathrm{C}_{2} \mathrm{H}_{5} \mathrm{OH}+2 \mathrm{H}_{2} \mathrm{O} \rightarrow 2 \mathrm{CH}_{3} \mathrm{COOH}+4 \mathrm{H}_{2}
$$


- $\quad$ acetogênese: oxidação de subprodutos da fase acidogênica (hidrogênio e acetato) em substratos apropriados para a próxima fase.

- metanogênese: transformação à gás carbônico e metano. Acetoclasticas (geram metano a partir do ácido acético) e hidrogenotróficas (geram metano a partir de gás carbônico e gás hidrogênio).

$2 \mathrm{CH}_{3} \mathrm{COOH} \rightarrow 2 \mathrm{CH}_{4}+\mathrm{CO}_{2}$ (descaboxilização do acetato)

$\mathrm{CO}_{2}+4 \mathrm{H}_{2} \rightarrow \mathrm{CH}_{4}+2 \mathrm{H}_{2} \mathrm{O}$ ( redução de $\mathrm{CO}_{2}$ )

- sulfetogênese: é uma fase indesejável que nem sempre ocorre. Ocorre na presença de enxofre e bactérias redutoras de sufato. Essas bactérias competem com as das fases de acetogênese e metanogênese.

$\mathrm{CH}_{3} \mathrm{COOH}+\mathrm{SO}_{4}^{-2}+2 \mathrm{H}^{+} \rightarrow \mathrm{H}_{2} \mathrm{~S}+2 \mathrm{H}_{2} \mathrm{O}+\mathrm{CO}_{2}$

É muito importante observar os fatores que influenciam a digestão anaeróbica, uma vez que se manipulados corretamente podem otimizar a produção do biogás aumentando a quantidade produzida e diminuindo o tempo gasto. Esses fatores são:

- temperatura: as bactérias metanogênicas, que são responsáveis pela produção de biogás, são muito sensíveis a rápida variação de temperatura. Uma variação de $3^{\circ} \mathrm{C}$ já é o suficiente para causar a morte da maioria das bactérias, conforme afirma Metz (2013). Por esse motivo a temperatura nos biodigestores deve ser controlada;

- tipo de resíduo: o resíduo é a matéria-prima utilizada pelas bactérias metanogênicas para a produção do biogás; portanto é imprescindível a escolha correta do tipo de resíduo. Tais resíduos orgânicos podem ser de origem animal ou vegetal oriundos da agropecuária, ambiente doméstico ou industrial;

- relação carbono/nitrogênio: Este fator é de grande importância para a formação de ácidos orgânicos utilizados pelas bactérias para a produção de biogás. Além disso, o carbono é utilizado pelas bactérias como energia e o nitrogênio é usado para a construção das estruturas celulares. A relação ideal está na faixa de 20 a 30 partes de carbono para uma de nitrogênio (METZ, 2013);

- pH: A faixa de pH para a sobrevivência das bactérias metanogênicas é de 6 a 8, sendo que 7 é o pH ideal para sua sobrevivência e produção do biogás;

- agitação: outro fator importante é a agitação da massa contida no reator, pois com a agitação se consegue uma liberação do gás preso no interior além de uma mistura homogênea do substrato e da população bacteriana, evitando assim a formação de crosta na superfície (MONROY, 2007);

- inibidores: a presença de antibióticos, detergentes e metais pesados podem inibir o processo de biometanização, algumas concentrações limites são apresentadas por Merege (2011);

- alcalinidade: a alcalinidade é a capacidade do sistema de suportar e amortizar a presença de ácidos, sem diminuir o $\mathrm{pH}$. Isto ocorre devido à presença de íons hidróxidos $\left(\mathrm{OH}^{-}\right)$, carbonatos $\left(\mathrm{CO}_{3}^{-2}\right)$ e bicarbonatos $\left(\mathrm{H}_{2} \mathrm{CO}_{3}{ }^{-}\right)$criando um efeito 
"tampão". Valores típicos de alcalinidade para digestão anaeróbica estão entre 1500 e 7500 mg $\mathrm{CaCO}_{3} / \mathrm{L}$ (MEREGE, 2011).

Biogás é definido como uma mistura gasosa leve, de fraca densidade, combustível, resultante da fermentação anaeróbica da matéria orgânica (CETESB, 2014). O Biogás é geralmente composto por: metano (40\% - 75\%), dióxido de carbono $(25 \%-40 \%)$, nitrogênio $(0,5 \%-2,5 \%)$, oxigênio $(0,1 \%-1 \%)$, ácido sulfídrico $(0,1 \%-0,5 \%)$, amoníaco $(0,1 \%-0,5 \%)$, monóxido de carbono $(0-0,1 \%)$,e hidrogênio ( $1 \%-3 \%)$ (CASTANON, 2002). Tendo em vista que o metano possui poder calorífico da ordem de $35800 \mathrm{~kJ} / \mathrm{m}^{3}$, o poder calorífico do biogás pode variar de 22500 a 25000 $\mathrm{KJ} / \mathrm{m}^{3}$. Isto significa um aproveitamento de 6,25 a $10 \mathrm{KWh} / \mathrm{m}^{3}$ (JORDÃO, 1995). Quando o $\mathrm{CO}_{2}$ é retirado da mistura gasosa, o poder calorífico do biogás pode atingir $60 \%$ do poder calorífico do gás natural (MEREGE, 2011; PREGNOLATTO, 1985).

O dióxido de carbono, gerado durante o processo de produção do biogás, é um subproduto indesejável por não ter capacidade de queima e não ser aproveitado em indústrias tradicionais de bebidas e alimentos, além de estar associado ao efeito estufa devido a seu poder de absorção de luz. A remoção da fração de dióxido de carbono no biogás aumenta o poder calorífico e, diminui o impacto ambiental (MEREGE, 2011; PREGNOLATTO, 1985). Na mistura gasosa gerada pode, também, estar presente o gás sulfídrico e gás hidrogênio, que afetam tanto a vida útil quanto o rendimento de tubulações usadas em armazenamento ou aparatos de queima (motores).

O sistema para remoção de gás carbônico e água presente na mistura é composto por uma coluna de borbulhamento acoplado ao fermentador/biodigestor contendo solução de hidróxido de bário, o qual é comumente utilizado na captação de dióxido de carbono em biodigestores rurais e industriais, ou mesmo em aterros sanitários (MACCARTY, 1991, OLIVEIRA, 2005). Há a formação de carbonato de bário $\left(\mathrm{BaCO}_{3}\right)$, de alta toxidade muito apreciado por indústrias de pesticidas, porcelanas, vidros e no controle de cromato em cromagem de peças industriais.

O processo de purificação do biogás leva em consideração o constituinte a ser removido, ou seja, a umidade e/ou gás sulfídrico e/ou gás carbônico, que serão definidos a seguir:

- Umidade: para cada emprego de utilização do biogás há uma definição para o grau de umidade aceitável, associado ao ponto de orvalho, e para tanto o mesmo deve ser seco (MURTO, 2004). São comuns as utilizações de glicóis, sílica gel ou outro produto que retenha umidade;

- Gás sulfídrico: neste processo a mistura gasosa passa por uma torre contendo óxido de ferro III $\left(\mathrm{Fe}_{2} \mathrm{O}_{3}\right)$ e raspas de madeira. $\mathrm{O}$ gás sulfídrico $\left(\mathrm{H}_{2} \mathrm{~S}\right)$ é injetado na base e ao caminhar pela torre reage com o óxido formando sulfeto de ferro III $\left(\mathrm{Fe}_{2} \mathrm{~S}_{3}\right)$. Este processo é considerado o mais barato para grandes volumes de gás sulfídrico. A reação química deste processo pode ser observada abaixo (OHWEILER, 1976, BACCAN, 1979, VOGEL, 1981):

$\mathrm{Fe}_{2} \mathrm{O}_{3}+3 \mathrm{H}_{2} \mathrm{~S} \rightarrow \mathrm{Fe}_{2} \mathrm{~S}_{3}+3 \mathrm{H}_{2} \mathrm{O}$

Após a formação do sulfeto de ferro III e, portanto, remoção do gás, o óxido de ferro III pode ser regenerado pela simples exposição da massa formada ao ar, segundo a seguinte equação:

$2 \mathrm{Fe}_{2} \mathrm{~S}_{3}+3 \mathrm{O}_{2} \rightarrow 2 \mathrm{Fe}_{2} \mathrm{O}_{3}+3 \mathrm{~S}_{2}$

A possibilidade de trabalho com quantidades fixas de reagentes (sistemas estáticos) faz com que esse sistema seja o de menor custo entre os sistemas até hoje idealizados e propostos. Existem sistemas, no entanto, menos econômicos e comprovadamente de maior eficiência, que 
são utilizados no meio acadêmico como objeto de pesquisa. Dentre esses, podemos citar o sistema constituído por nitrato de chumbo que possui alta sensibilidade e rendimento (> 90\%), representado na Equação (8) (OHWEILER, 1976). O produto formado apresenta ausência de cor (precipitado negro de sulfeto de chumbo), e é de fácil visualização.

$$
\mathrm{Pb}\left(\mathrm{NO}_{3}\right)_{2}+\mathrm{H}_{2} \mathrm{~S} \rightarrow \mathrm{PbS}+2 \mathrm{HNO}_{3}
$$

Outro meio de retirar o gás sulfídrico é a lavagem do gás em hidróxido de potássio. 0 produto resultante pode ser enriquecido com enxofre e potássio e utilizado como biofertilizante.

Gás carbônico: entre as diversas maneiras usadas para remover gás carbônico podemos citar o lavado com água, processo simples de remover impurezas, mas que consome grande quantidade de água e também é dependente de pressão e temperatura (CRAVEIRO, 1982, OLIVEIRA, 2005). Como o biodigestor trabalha com pressão e temperatura elevadas grandes quantidades de gás carbônico são adsorvidas pela água, que se torna corrosiva, problema para condução e descarte.

Outra maneira e já mencionado anteriormente, envolve reação com hidróxido de bário com formação de carbonato de bário, precipitado insolúvel. A equação entre gás carbônico e hidróxido de bário está representada na Equação (9) (OHWEILER, 1976, MORITA, 1976, HARRIS, 2005).

$$
\mathrm{Ba}(\mathrm{OH})_{2}+\mathrm{CO}_{2} \rightarrow \mathrm{BaCO}_{3}+\mathrm{H}_{2} \mathrm{O}
$$

Quando o gás carbônico reage com soluções de alguns hidróxidos, seja de potássio ou cálcio, ocorre a formação de bicarbonato, em uma reação reversível. Com tempo de reação suficientemente grande estes sistemas permitem inclusive a remoção de sulfetos. Estes processos são apresentados nas Equações (10), (11) e (12).

$$
\begin{aligned}
& 2 \mathrm{NaOH}+\mathrm{CO}_{2} \rightarrow \mathrm{Na}_{2} \mathrm{CO}_{3}+\mathrm{H}_{2} \mathrm{O} \\
& \mathrm{Na}_{2} \mathrm{CO}_{3}+\mathrm{CO}_{2}+\mathrm{H}_{2} \mathrm{O} \rightarrow 2 \mathrm{NAHCO}_{3} \\
& \mathrm{H}_{2} \mathrm{~S}+\mathrm{Na}_{2} \mathrm{CO}_{3} \rightarrow \mathrm{NaHS}+\mathrm{NaHCO}_{3}
\end{aligned}
$$

Destes hidróxidos, o de cálcio, é o mais barato, mas a formação de seu sal por precipitação, pode causar entupimento dos dispositivos de transporte (CRAVEIRO, 1982). Podem também ser utilizados solventes orgânicos, mas sua alta taxa de corrosão tornam os sistemas economicamente inviáveis.

De acordo com a literatura as concentrações produzidas de gases, para sistemas com biomassa pós digestão animal (estercos), são: $70 \%$ de $\mathrm{CH}_{4}\left(0,35 \mathrm{~L}\right.$ ou $0,01565 \mathrm{~mol}$ ), $25 \%$ de $\mathrm{CO}_{2}$ $(0,125 \mathrm{~L}-0,005580 \mathrm{~mol}$ ou $0,24552 \mathrm{~g}), 3 \%$ de $\mathrm{H}_{2} \mathrm{~S}(0,015 \mathrm{~L}-0,0006960 \mathrm{~mol}$ ou $0,02366 \mathrm{~g})$ e $2 \%$ de $\mathrm{H}_{2}(0,0010 \mathrm{~L}-0,0004464 \mathrm{~mol})$ (CRAVEIRO, 1982).

Em um trabalho anterior, realizado por este grupo de pesquisa, utilizando biodigestores alimentados com arroz cozido (biomassa não digerida) na proporção de 1:2, ou seja, $100 \mathrm{~g}$ de arroz cozido para $200 \mathrm{~g}$ de água obteve-se cerca de 0,5 L de gás após 30 dias (GUEDES, 2015).

Portanto, em função do exposto, neste trabalho será apresentada uma proposta para remediação do biogás oriundo de biomassa não digerida. 


\section{METODOLOGIA}

Todos os experimentos foram realizados em laboratório, à temperatura ambiente $(25 \circ \mathrm{C} \pm$ 3 으) e com luminosidade controlada, sem exposição externa.

A matéria orgânica (biomassa não digerida) utilizada foi $100 \mathrm{~g}$ de arroz cozido, triturado por $90 \mathrm{~s}$ em liquidificador residencial com adição de $200 \mathrm{~mL}$ de água potável, segundo metodologia descrita por Guedes (2015).

Para a remediação do biogás foi montado um sistema com base em reações de precipitação de gás carbônico e sulfetos, embora não seja a técnica mais comum de remediação, permite a obtenção de produtos de apreço comercial (carbonato de bário e sulfeto de chumbo). Foi definido pontos de coleta de gases que permitirão a obtenção de frações de gases gerados para posterior análise por cromatografia de fase gasosa. O controle do fluxo de gás em cada etapa garante a contenção da mistura de gases por tempo suficiente para que as reações ocorram.

As concentrações de $\mathrm{Ba}(\mathrm{OH})_{2}$ e $\mathrm{Pb}\left(\mathrm{NO}_{3}\right)_{2}$ utilizadas foram calculadas de acordo com as equações 9 e 10, respectivamente, e, levando em consideração a produção máxima de $\mathrm{CO}_{2}(25 \%)$ e $\mathrm{H}_{2} \mathrm{~S}(3 \%)$, encontrado na literatura (CRAVEIRO, 1982). As massas obtidas de $\mathrm{BaCO}_{3}$ e $\mathrm{PbS}$ são indicativas para as concentrações de $\mathrm{CO}_{2}$ e $\mathrm{H}_{2} \mathrm{~S}$ remediadas por via química e o valor $0,24 \mathrm{~g}$ (25\%) para $\mathrm{CO}_{2}$ permite o cálculo da concentração de $\mathrm{Ba}(\mathrm{OH})_{2}$ usado no aparato experimental, segundo Equação (9).

$$
\begin{array}{ccc}
\mathrm{Ba}(\mathrm{OH})_{2} & +\mathrm{CO}_{2} \rightarrow \mathrm{BaCO}_{3}+\mathrm{H}_{2} \mathrm{O} \\
171,32 \mathrm{~g} & 44 \mathrm{~g} & 197,34 \mathrm{~g} \\
\mathrm{x} & 0,24 \mathrm{~g} &
\end{array}
$$

$x=0,93 \mathrm{~g}$ de hidróxido de bário com 10\% de erro (massa excedente) =1,03 g

Para o cálculo da concentração de $\mathrm{H}_{2} \mathrm{~S}$ foi usado o valor $0,024 \mathrm{~g}(3 \%)$ do volume total de gases gerados (CRAVEIRO, 1982) e que possibilita a quantização da concentração da solução para remediação deste gás por precipitação quantitativa segundo cálculos apresentados, segundo Equação (8).

$$
\begin{aligned}
& \mathrm{Pb}\left(\mathrm{NO}_{3}\right)_{2}+\mathrm{H}_{2} \mathrm{~S} \rightarrow \mathrm{PbS}+2 \mathrm{HNO}_{3} \\
& 331,2 \mathrm{~g} \quad 34 \mathrm{~g} \quad 239,3 \mathrm{~g} \\
& \text { y } \quad 0,024 \mathrm{~g} \\
& y=0,234 \mathrm{~g} \text { de nitrato de chumbo com } 10 \% \text { de erro (massa excedente) }=0,26 \mathrm{~g}
\end{aligned}
$$

De acordo com os cálculos acima, na coluna de borbulhamento utilizou-se uma solução contendo $1,03 \mathrm{~g} / \mathrm{L} \mathrm{Ba}(\mathrm{OH})_{2}$ para captar $\mathrm{CO}_{2}$ do sistema, com o intuito de remover sulfetos utilizouse uma solução contendo $0,26 \mathrm{~g} / \mathrm{L}$ de $\mathrm{Pb}\left(\mathrm{NO}_{3}\right)_{2}$, ambas as soluções foram preparadas com excedente de $10 \%$ como forma de garantir a precipitação quantitativa dos gases de interesse.

A Figura 1 ilustra o sistema utilizado composto por: (1) biodigestor, (1a) ponto de amostragem de biomassa para extração de biomassa e monitoramento de $\mathrm{pH}$, (1b) ponto de amostragem de biogás gerado, (2) coluna de borbulhamento, (2a) ponto de amostragem de biogás após remoção da fração de $\mathrm{CO}_{2}$, (3) recipiente para a remoção de sulfetos por precipitação de $\mathrm{PbS}$, (3a) um ponto de amostragem de gás sem $\mathrm{CO}_{2}$ e $\mathrm{S}^{2-}$, (4) recipiente contendo sílica gel para remoção 
de umidade $\left(\mathrm{H}_{2} \mathrm{O}\right)$ e (4a) um ponto de amostragem de gás sem $\mathrm{CO}_{2}$ e $\mathrm{S}^{2-}$ e $\mathrm{H}_{2} \mathrm{O}$ removidos por precipitação e adsorção física.

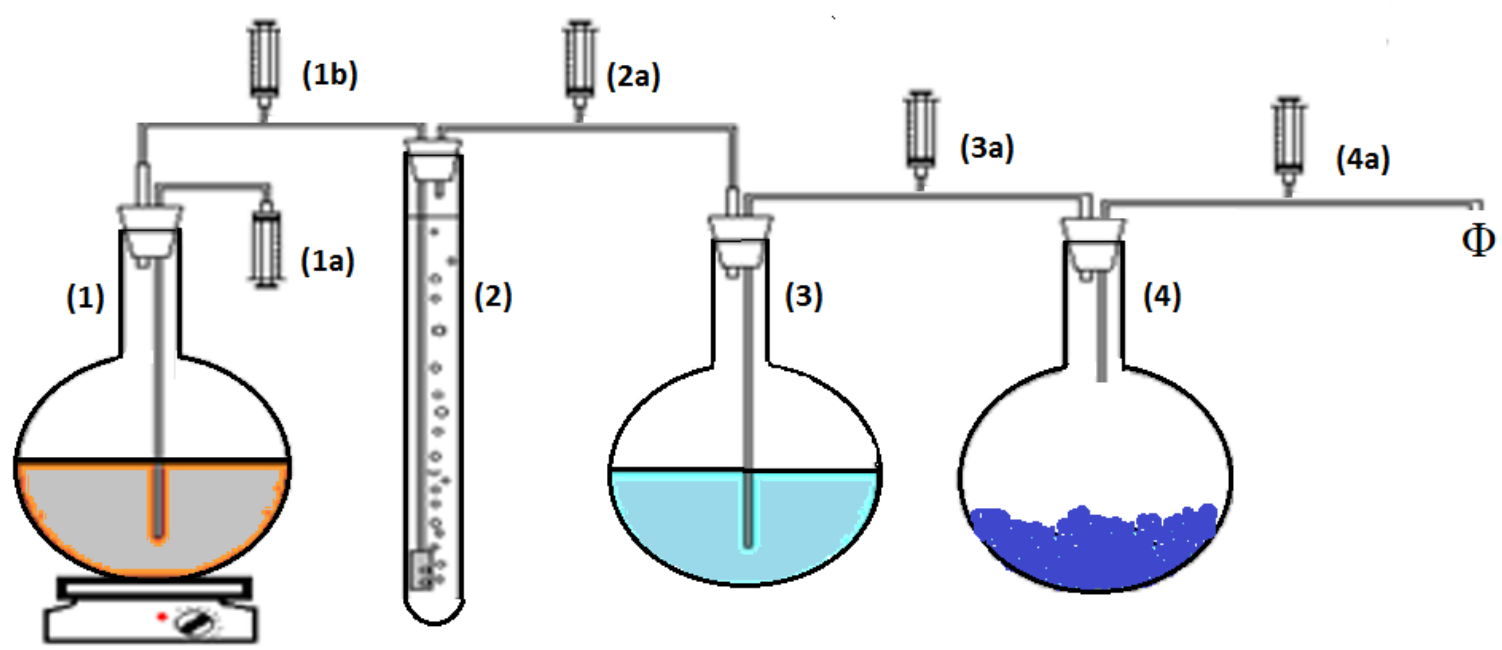

Figura 1: Sistema experimental para fracionamento de biogás, contendo: (1) balão com biomassa e água; (1a) seringa para extração de biomassa; (1b) seringa para extração de biogás gerado; (2) proveta com solução contendo $\mathrm{Ba}(\mathrm{OH})_{2} ;(2 \mathrm{a})$ seringa para extração de biogás sem $\mathrm{CO}_{2} ;(3)$ balão contendo solução $\mathrm{Pb}\left(\mathrm{NO}_{3}\right)_{2} ;(3 a)$ seringa para extração de biogás sem sulfetos; (4) balão contendo sílica gel para extração de umidade $\left(\mathrm{H}_{2} \mathrm{O}\right)$ e $\left(4^{\mathrm{a}}\right)$ seringa para extração do gás metano puro

Após 720 h (30 dias) o sistema foi aberto e o borbulhamento ocorreu por fases. Primeiro na coluna de remediação de gás carbônico e somente depois de todo precipitado de $\mathrm{BaCO}_{3}$ ter sido formado abriu-se o sistema para precitação do gás sulfídrico na forma de sulfeto no segundo balão. $\mathrm{E}$, por último houve a passagem do gás no terceiro balão contendo sílica gel. Com esse procedimento pretende-se obter gás metano praticamente puro no final do processo.

Nos pontos 1b, 2a, 3a e 4a ilustrado na Figura 1, o biogás foi coletado para posterior análise por cromatografia de fase gasosa. Na quantização do gás $\mathrm{CO}_{2}$ removido, a mistura permaneceu em banho-maria por uma hora e depois em repouso por $12 \mathrm{~h}$ para digestão do precipitado, filtrada em papel de filtro quantitativo faixa azul. Sequencialmente o precipitado foi lavado com água quente (100 ml) em pequenas porções e depois com álcool, seco em estufa a 110 ㄷ c por $2 \mathrm{~h}$.

O mesmo processo de filtragem e secagem utilizados na remoção de $\mathrm{CO}_{2}$ foram adotados para o processo de quantização do precipitado de chumbo, remoção de sulfetos

\section{RESULTADOS E DISCUSSÕES}

O volume total de gás produzido foi de aproximadamente $0,5 \mathrm{~L}$, confirmando o volume médio observados em sistemas anteriores que se mostraram reprodutíveis e confiáveis por não apresentarem vazamentos. Em um espaço amostral de 15 biodigestores a variação máxima foi de $20 \mathrm{~mL}$ (GUEDES, 2015).

As massas obtidas para carbonato de bário e sulfeto de chumbo foram respectivamente 0,5945 g e 0,1832 g, corroborando com os cálculos realizados previamente. 
Segundo as concentrações adotadas para as soluções reagentes de hidróxido de bário e nitrato de chumbo e as massas obtidas pós remediação dos gases gerados por decomposição de biomassa, fermentação de arroz cozido, foi possível mensurar a concentração parcial dos gases dióxido de carbono e sulfetos. As porcentagens das frações de gases obtidas para sistemas com biomassa pós digestão animal e sem digestão, são apresentadas na Figura 2.

A quantidade de precipitado, carbonato de bário, obtida 0,5945 g corresponde a precipitação de $0,1325 \mathrm{~g}$, ou seja $13,5 \%$ de $\mathrm{CO}_{2}$ quantidade esta, inferior à média apresentada como referência (CRAVEIRO, 1982), cerca de $25 \%$. O precipitado de sulfeto de chumbo, igual a $0,1521 \mathrm{~g}$ corresponde a remediação de $0,02161 \mathrm{~g}$ de sulfeto, ou seja cerca de $2,7 \%$ de $\mathrm{H}_{2} \mathrm{~S}$ quantidade esta, inferior aos $3 \%$ adotados como referência (YADVIKA, 2004).

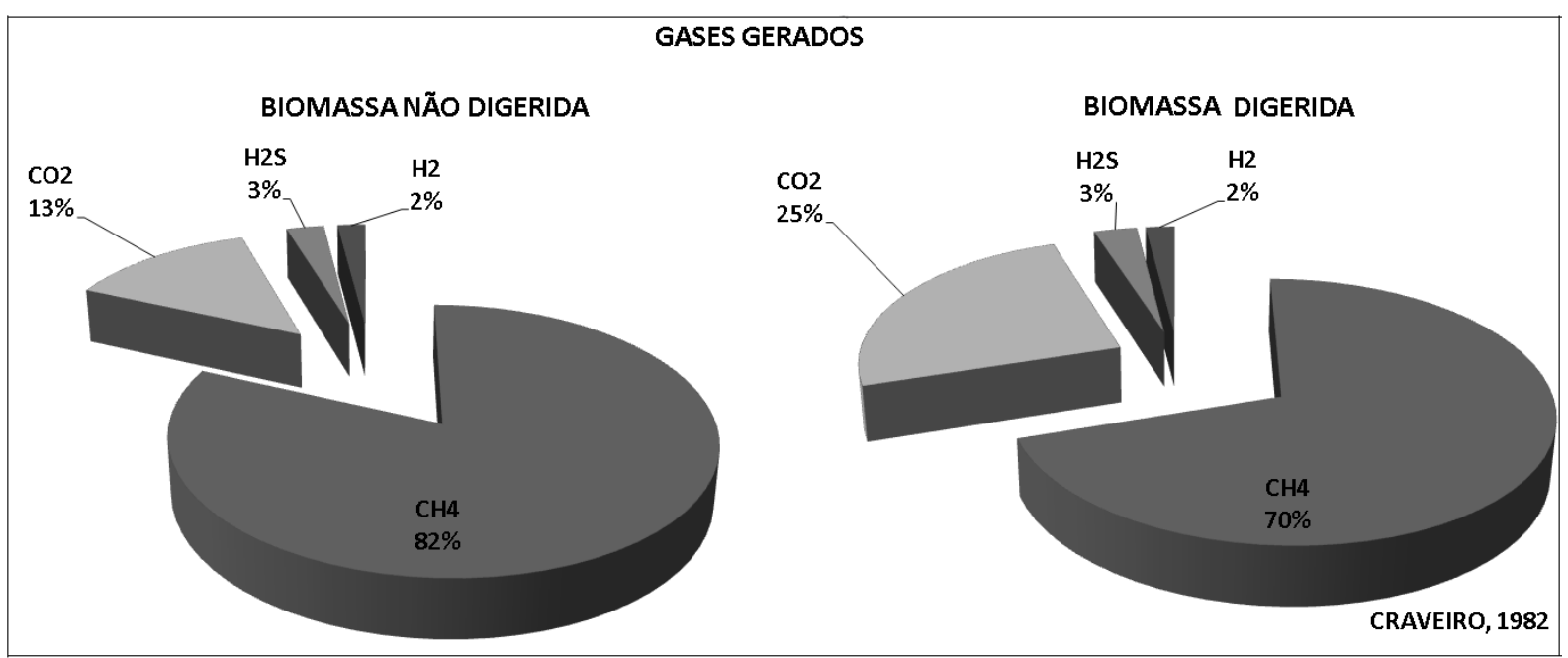

Figura 2: Concentração de gases gerados, metano, dióxido de carbono, sulfetos e hidrogênio, obtidos partindo de biomassa não digerida (arroz cozido) em comparação com biomassa digerida (esterco suíno) (CRAVEIRO, 1982).

Foi possível observar que a relação em massa de água e biomassa adotadas garante uma produção final de biogás após 30 dias $(720$ h) sem variações consistentes de volume e, portanto, são reprodutíveis. As frações parciais dos gases gerados, quando comparados a referência adotada, foram inferiores tanto para $\mathrm{CO}_{2}$ e para $\mathrm{H}_{2} \mathrm{~S}$. Isso deve-se principalmente, pelo fato do sistema estudado partir de biomassa não digerida possuir maior valor calórico, convertido via fermentação em maior volume final de gás metano.

\section{CONCLUSÕES}

O sistema experimental criado para o fracionamento de biogás mostrou-se eficiente, reprodutivo e de fácil operação. Durante as etapas de fracionamento as quantidades de reagentes foram suficientes para reações estequiométricas e permitiram mensurar a quantidade de biogás gerado segundo diferentes biomassas. Sistemas alimentados por biomassa não digerida (arroz cozido) geraram maior volume de biogás comparativamente a biomassa digerida (esterco suíno) da literatura. Estes resultados mostram a potencialidade do uso de rejeitos residenciais como gerador de biogás propiciando economia para as famílias e destino apropriado para rejeitos deste tipo. 


\section{REFERÊNCIAS BIBLIOGRÁFICAS}

1. AULIVE - http://aulive.com . Acessado em 7 de janeiro de 2015.

2. BACCAN, N. et al. Química Analítica Quantitativa Elementar. São Paulo: Edgard Blücher; Campinas: Universidade Estadual de Campinas, 1979.

3. CASTANON, N.J.B. Biogás, originado a partir dos rejeitos rurais. Trabalho na disciplina: Biomassa como fonte de energia - Conversão e utilização. São Paulo: Universidade de São Paulo, 2002.66p.

4. CETESB - Companhia de Tecnologia de Saneamento Ambiental de São Paulo, Biogás. http://www.cetesb.sp.gov.br/mudancas-climaticas/biogas/Biog\%C3\%A1s/17-

Defini\%C3\%A7\%C3\%A3o. Acessado em 25 de novembro de 2014.

5. CRAVEIRO, A.M. Considerações sobre projetos de plantas de biodigestão - Digestão anaeróbica aspectos teóricos e práticos. I Simpósio Latino-Americano sobre a produção de Biogás a partir de resíduos orgânicos, São Paulo, dezembro de 1982.

6. HARRIS, D. C. Análise Química Quantitativa: 6a ed. Rio de Janeiro: LTC, 2005.

7. GUEDES, M. F.; SANTO, L.S.E.; PEREIRA, V.; MARTINEZ, G.A.S.; TOMACHUK, C.R.; Sistema anaeróbico caseiro para produção de biogás a partir de biomassa de arroz. In: Anais do XI Congresso Brasileiro de Engenharia Química em Iniciação Científica (Blucher Chemical Engineering Proceedings, v. 1, n. 3]. ISSN Impresso: 2446-8711. São Paulo: Blucher, 2015. ISSN 2359-1757, DOI 10.5151/chemeng-cobeqic2015-482-34189-266152

8. MACCARTY, P.L., MOSEY, F.E. Modelling of anaerobic digestion process (a discussion of concepts). Water Science and Technology, v. 24, p. 17-33, 1991.

9. MEREGE, R.V. Estratégias para Medição de Biogás e Degradabilidade da Matéria Orgânica em Reatores Anaeróbicos. São Carlos, 2011. Monografia apresentada ao curso de graduação em Engenharia Ambiental da Escola de Engenharia de São Carlos da Universidade de São Paulo, 2011.

10. METZ, H.L. Construção de um Biodigestor Caseiro para a Demonstração da Produção de Biogás e Biofertilizante em Escolas Situadas em Meios Urbanos. Lavras, 2013. Monografia apresentada à Universidade Federal de Lavras, 2013.

11. MORAES, P.B. Digestão anaeróbica. Departamento de Tecnologia em Saneamento Ambiental, Centro Superior de Educação Tecnológica, UNICAMP Limeira. (http://webensino.unicamp.br/disciplinas/ST502-293205/apoio/9/digest_o_anaer_bia.pdf). Acessado em 06 de janeiro de 2015.

12. MORITA, T.; ASSUMPÇÃO, R, M. V. Manual de soluções reagentes e solventes: padronização, preparação, purificação. 2. ed. São Paulo: E. Blücher, 1976, 627 p.

13. MURTO, M., BJORNSSON, L., MATTIASSON, B. Impact of Food industrial waste on anaerobic co-digestion of sewage sludge and pig mature. Journal of Environmental Management, v. 70, p. 101-107, 2004.

14. OHWEILER, O. A. Química analítica quantitativa. 2. ed. Rio de Janeiro: Livros técnicos e científicos. v. 2, 1976, 664p.

15. OLIVEIRA, L.R.P., Biodigestor, Seminários Técnicos de Suinocultura, VII Simpósio Goiano de Avicultura e II Simpósio Goiano de Suinocultura. Goiânia, Goiás, 13 a 15 de setembro de 2005. 
16. PREGNOLATTO, W., PREGNOLATTO, N. Métodos químicos e físicos para análise de alimentos. In: Normas analíticas do Instituto Adolfo Lutz. 3. ed. São Paulo: Instituto Adolfo Lutz, 1985. v. 1.

17. RIBEIRO, D. S. DETERMINAÇÃO DAS DIMENSÕES DE UM BIODIGESTOR EM FUNÇÃO DA PROPORÇÃO GÁS/FASE LÍQUIDA. HOLOS, ano 27, v. 1, p. 49, 2011.

18. SAKA, V. Biodigestor compacto. Patente BR102013021110A2, 4 de novembro de 2013.

19. HONDA, T. Aperfeiçoamento em biodigestor anaeróbico utilizado para captação de biogás. Patente BRPI0703021A2, 9 de fevereiro de 2009.

20. VOGEL, A. I. Análise inorgânica quantitativa: Incluindo análise instrumental elementar. Rio de Janeiro: Guanabara, 4‥ Ed, 1981, 690p.

21. YADVIKA; SANTOSH; SREEKRISHNAN, T. R.; KOHLI, S.; RANA, V. Enhancement of biogas production from solid substrates using different techniques - a review. Bioresource Technology, v. 95, p. 1-10, 2004. 